\title{
Laveran, Marchiafava y el paludismo
}

\author{
Walter Ledermann D.
}

\begin{abstract}
Recibido: 24 marzo 2008 Aceptado: 26 marzo 2008
\end{abstract}

Correspondencia a: Walter Ledermann D oncemayor@gmail.com

\section{Laveran, Marchiafava and the paludism}

The discovery in 1880 of the malaria parasite by the French investigator Alphonse Laveran found for almost ten years the obstinate refusal from the italian Ettore Marchiafava, who saw in the parasitic elements only degenerative forms of the erythrocytes. The acknowledgement for Laveran came in 1889 with the Bréant Prize and later the Nobel of 1907, half of which he gave to the Pasteur Institute. By his side, Marchiafava demonstrated the transmission of malaria man to man by the blood of the sick, through experiences to day inadmissible for any ethical committee. From the classic textbook of Laveran Du paludisme et de son hématozoaire, published in 1891, the history of this discovery is revised in the author's words.

Key words: malaria, paludism, history, Laveran, Marchiafava.

Palabras clave: malaria, paludismo, historia, Laveran, Marchiafava.

"A l término del año 1880 he señalado en la sangre de los enfermos afectados por fiebre palustre, parásitos nuevos, y he vuelto en varias ocasiones sobre la descripción de estos parásitos, para confirmar mis primeras observaciones y para completarlas en algunos puntos.

Los parásitos descritos por mí como los del paludismo difieren mucho de los descritos anteriormente, y no entran en la clase de los schizophytes, donde todos los microbios patógenos parecían entonces

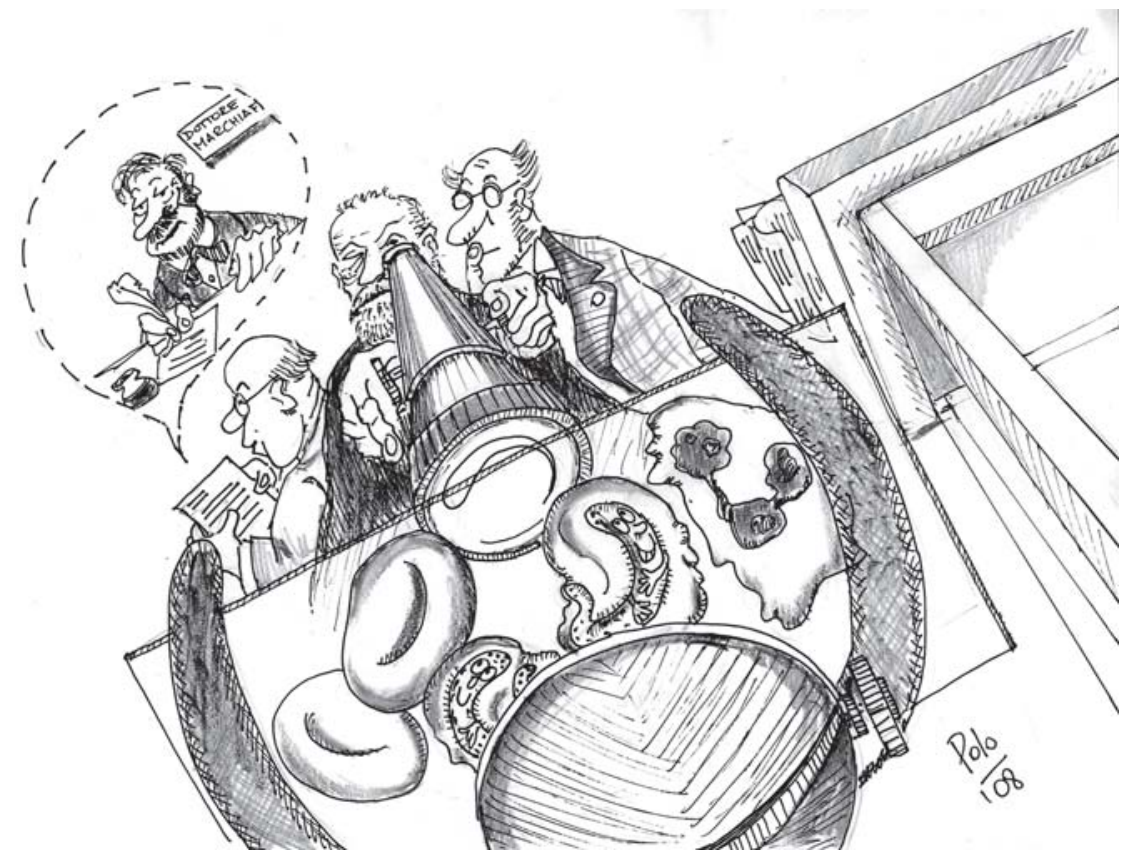

tener que clasificarse; también mis primeras afirmaciones fueron acogidas por doquiera con mucho escepticismo".

Así comienza Laveran el prefacio de su obra capital “Du paludismo et de son hématozoaire", editada por Masson, librero de la Academia de Medicina, en el París de $1891^{1}$, cuando ya la aceptación de su parásito era universal, más que todo por haber ganado en 1889 el famoso Premio Bréant de la Academia de Ciencias, la máxima distinción científica de una época en que el Premio Nobel no existía, y que el francés llegaría a ganar posteriormente, en 1907, por el mismo descubrimiento. En el prefacio de su libro, el autor, lleno de orgullo, reproduce las palabras del profesor Bouchard al otorgarle el Premio:

"La comisión, por un voto unánime, discierne el Premio Bréant (renta de la fundación) a M. Laveran, profesor de la Escuela de Val-de-Grâce, por su descubrimiento de los hematozoarios del paludismo. Este descubrimiento, que data de diez años, ha sido controlado por los más diversos observadores, en casi todos los países donde reina la fiebre intermitente. El parásito, agente patógeno de esta endemia, la más antigua, la más extendida y la más grave de todas las que han afligido a la humanidad, difiere radicalmente de todos los parásitos actualmente conocidos de otras enfermedades infecciosas. Es, al menos en el hombre, el primer ejemplo de una enfermedad causada por un esporozoario. Nadie sostiene ya hoy día las ideas emitidas anteriormente, que atribuían la enfermedad palúdica a diversas formas de algas o de bacterias..."2. 
Charles Louis Alphonse Laveran fue uno de tantos investigadores europeos de la edad de oro de la microbiología, a fines del siglo XIX, cuando la medicina ardía en una fiebre de descubrimientos, que se caracterizaron por compatibilizar afanes militares y aventureros con los científicos, combinación indispensable para estudiar enfermedades tropicales o exóticas en las colonias, entre los cuales brillan los nombres de Yersin, Calmette, Bruce, Pfeiffer... Este Laveran de la Tour, que en nada desmerece ante ellos, nació en París el 18 de junio de 1845, en una familia de médicos Laveran y de militares de la Tour. Su padre, Louis Théodore Laveran, era médico militar, Director de la Escuela de Val de Grace, y tuvo una destinación en Argelia cuando Charles Alphonse era muy niño: allí el futuro investigador conocería el embrujo del desierto y de lo exótico, así como el encanto del ejercicio médico en situaciones extremas, al ver a su padre en acción. De este modo predestinado, fue médico, tras estudiar en Estrasburgo y titularse en 1867 con una tesis sobre la regeneración de nervios ${ }^{3}$.

Tres años después estalló la guerra franco-prusiana y el joven Laveran se encontró metido en el centro del huracán. Recordemos que Estrasburgo se encuentra en Alsacia, provincia que, junto a Lorena, ha sido siempre fuente de disputa entre Francia y Alemania. Para entenderlo mejor, leamos un periódico regional de esa época, Le Courrier du Bas-Rhin:

“¿Cómo ha recibido la población de Strasbourg la declaración de guerra ?... Con una dolorosa angustia, se puede decir con toda sinceridad. Conocemos las fuerzas de Alemania, nosotros sabemos más y mejor que el resto de Francia cuáles eran sus proyectos y sus reivindicaciones, pues, más que nadie, estábamos expuestos a los sarcasmos de nuestros vecinos al otro lado del Rhin, que jamás perdían una ocasión de decirnos que esta "tierra alemana” debería volver un día a la madre patria. "Ustedes son alemanes”, nos decían, "vuestras costumbres, vuestro lenguaje, testimonian vuestro origen alemán y deben esperar con impaciencia ser liberados del yugo de los alsacianos”... Quienes tenían ese propósito olvidaban que la Revolución de 1789 y los campos de batalla habían fusionado el elemento alsaciano con el elemento galo y que, si nuestro acento era todavía duro y nuestras costumbres recordaban las de la antigua ciudad libre alemana, estábamos estrechamente unidos por los sentimientos al bello país que había proclamado los derechos del hombre..."4.

Laveran, como hombre de honor, se enroló de inmediato en defensa de su patria; como médico e investigador, aventuramos que pudo haber dudado de la justificación de las guerras y analizado la ambigua situación de los ciudadanos de Estrasburgo. Designa- do oficial de ambulancia, fue enviado a Metz, donde participó en las batallas de Gravelotte y de Saint-Privat, así como en el sitio de dicha ciudad, tras cuya capitulación fue enviado de regreso a Francia, ejerciendo su profesión en Lille y luego en París, donde ganó el concurso para la Cátedra de Enfermedades Militares y Epidémicas en Val de Grâce, que antes ocupara su padre. Y de allí partió en 1878 para Bône, en Argelia, pues había sentido the call of the wild, $\mathrm{y}$ durante cinco o seis años buscó, hasta encontrarlos, los parásitos del paludismo, cuya existencia confirmó durante un breve viaje a Italia, en el hospital San Spirito. Sería el comienzo de una larga lucha contra la incredulidad de sus pares.

"En 1878 -relata Laveran en su libro-después de haber terminado mi período como agregado en la Escuela de Medicina de Val de Grâce, fui destinado a Argelia, a cargo de un Servicio en el Hospital de Bône. Un gran número de mis enfermos estaba afectado de fiebres palustres y me sentí fuertemente obligado a su estudio, ya que en Francia sólo había observado formas raras y benignas de la enfermedad. Tuve entonces la ocasión de practicar la autopsia a individuos fallecidos a causa de la fiebre perniciosa y de estudiar la melanesia, esto es, la formación de pigmento negro en la sangre, ya descrita por varios observadores, sin que fijaran la constancia de esta alteración ni la causa de la producción de pigmento...".

Con dedicación y constancia estudiaba Laveran estos pigmentos desde las primeras horas de la mañana, y en esas horas, el 6 de noviembre de 1880, examinando leucocitos "melaníferos", quedó absolument épaté al constatar que algo se movía : "al lado de estos corpúsculos esféricos, hialinos, sin núcleo, de ordinario pigmentados, observé filamentos móviles o flagelos, cuyos movimientos extremadamente vivos y variados, no me dejaron ninguna duda sobre la naturaleza animada de estos elementos”.

Comunicó su observación por primera vez en 1881, mediante una comunicación a la Academia de Medicina, que luego publicó la antigua y prestigiosa editorial top de París, la Maison Ballière et fils, en octavo, 104 páginas, con dos láminas: Nature parasitaire des accidentes de l'impaludisme. Description d'un nouveau parasite trouvé dans le sang des maladies atteints de fiebre palustre ${ }^{5}$. En ella describía a sus parásitos como "pequeños elementos, que miden apenas la sexta parte de un hematíe y que no contienen más que uno o dos granos de pigmento, y que no parecen representar sino una de las fases de cuerpos esféricos más grandes; tanto libres como adosados a los hematíes, se encuentran a veces tres o cuatro de ellos sobre un mismo hematíe, y presentan a la temperatura ordina- 
ria movimientos ameboideos”. El parásito, así presentado al mundo científico y denominado en un principio por su descubridor Oscillaria, debió enfrentar a numerosos candidatos patrocinados por distintos investigadores: los diplococos del ilustre Babes, el Bacillus malariae de Klebs y Crudeli, el Micrococcus de Marchiafava y Celli...

El gran anátomo patólogo italiano Ettore Marchiafava (1847-1935) fue su rival más enconado y le dio guerra por casi diez años, secundado por Celli, Golgi y Grassi. Para el investigador italiano, los supuestos parásitos del francés no eran sino "hematíes degenerados”, y los supuestos flagelos, sólo parte de esta degeneración filamentosa: en otras palabras, los glóbulos rojos “mostraban la hilacha”. En 1884, en compañía de Celli, publicó sus observaciones en forma de una memoria: "Sulle alterazioni dei globuli rossi nelle infezione da malaria e sulla genesi della melanemia”, que al año siguiente reprodujo en alemán, idioma por entonces de mayor difusión en el campo microbiológi$\mathrm{CO}^{6}$.

Laveran replicaba con hechos y en la página 197 de su Tratado de fiebres palustres, refiere: "sobre 480 palúdicos examinados en Argelia, he constatado 432 veces la existencia de los parásitos; sobre 79 exámenes hechos tiempo antes de un acceso febril, he observado parásitos 79 veces; sobre 286 exámenes durante el acceso, 273 veces; sobre 164 algunas horas después del acceso, 141 veces"...7. "Y todos se movían”, le faltó agregar, pues éste era el argumento de mayor peso.

Ambos sabios, muy caballeros, intercambiaron regalos, como relata el mismo Laveran: "En una carta fechada en Roma, 9 de Abril de 1884, M. Marchiafava, agradeciéndome el envío de mi Traité des fiebres palustres y enviándome su mencionada Memoria..., ha tenido buen cuidado de hacerme notar que él ha llegado, con su colaborador, a conclusiones muy diferentes de las mías. Para nosotros -me escribe $M$. Marchiafava- los únicos elementos sospechosos de ser parásitos son des corpuscules privés de pigment, analogues à des microcoques, que se encuentran en gran número en los glóbulos rojos... (y) creemos que las formas pigmentadas que usted ha descrito no son más que glóbulos rojos degenerados y pigmentados”.

En 1885, Marchiafava y Celli publican en los Anales Italianos de Agricultura una segunda Memoria, "Nuevas investigaciones sobre la infección malárica”, reconocen las descripciones de Laveran, insisten en sus micrococos, pero confiesan que de 47 de éstos, 40 son pigmentados: ya es un comienzo. En la tercera Memoria, 1886, reconocen los movimientos ameboides y hablan de "hemoplasmodios maláricos"; y en 1887, en una comunicación a la Academia Real de Roma, se rinden a los hechos, pero no a Laveran, reconociendo que la malaria es causada por parásitos y que estos elementos no son degeneraciones de los glóbulos rojos. Pero, agregan, estos parásitos, los verdaderos agentes etiológicos, no son los mismos descritos por Laveran: en otras palabras, se adjudican la autoría con sus plasmodios ${ }^{8}$.

La rendición, como vemos, dista de ser total y la lucha continúa, detalle por detalle de los parásitos, hasta el año 1889, cuando ya Guarnieri había reemplazado a Marchiafava, aunque Laveran pensaba que éste seguía maniobrando en las sombras, inspirando a sus compatriotas.

En realidad, pocas veces se han visto en la historia de la microbiología porfiados más grandes que los contrincantes de Laveran. Al final, el francés no puede evitar un comentario ácido: "No les queda más a Celli y a Guarnieri que confesar un hecho, y es que Marchiafava había tenido gran culpa de oponerse durante tanto tiempo a los hechos avanzados por mí y que las reivindicaciones de este observador sobre el tema de los plasmodios no tenían base alguna”. Sin embargo, al final el italiano ganó la autoría del género Plasmodium, desplazando a la Haemamoeba laverani ${ }^{9}$.

En realidad, era imposible continuar negando la evidencia, que sabios como Metchnikoff y Pasteur habían reconocido al ver una sola de las preparaciones de Laveran, confirmando las palabras de Soulié: “Es imposible no convencerse, cuando se les ha visto una vez, de su existencia y de naturaleza viva. Es un espectáculo muy curioso contemplar esos largos brazos agitándose con tanto vigor alrededor de la esfera que los sostiene, capaces de tironear y de dar todas las formas a uno o varios glóbulos situados en su vecindad. A veces uno de los flagelos se desprende y sigue su marcha en tirabuzón en el suero, separando los glóbulos que encuentra a su paso, asumiendo la forma de un espirilo..."10.

Ettore Marchiafava no era porfiado sin razón. Era un brillante, aplicado y racional anatomopatólogo; seguía rigurosamente el método científico y no aceptaba nada sin demostrar su realidad con pruebas y contrapruebas; tenía todo un equipo de excelentes colaboradores, un buen laboratorio y mejores microscopios que Laveran. Éste, en cambio, trabajaba prácticamente solo, con tenacidad infatigable, repitiendo observación tras observación, en espera del hallazgo fortuito... que al fin llegó. Vistos desde la distancia de los años, el italiano era un científico más "moderno” y el francés más “romántico”. Pero no debemos desprender de esta comparación que Marchiafava era un cabeza cuadrada, absorto en el tema médico: era un hombre muy culto, de gran avidez intelectual, capaz de solazarse en 
investigaciones “más allá de la medicina”, como lo demuestra una de sus últimas publicaciones, que analizaba las referencias al vino presentes en la obra del poeta clásico Horacio ${ }^{9}$.

Marchiafava vivió, siempre en Roma, entre 1847 y 1935. Ya en su doctorado ganó una medalla de oro, luego hizo "una pasadita” por Berlín, para interiorizarse en los métodos de Koch, y allí le nació el interés por la microbiología. Además del Plasmodium, tiene brillantes descripciones en arteritis sifilítica cerebral, degeneración del cuerpo calloso en los alcohólicos (enfermedad de Marchiafava-Bignami), hemoglobinuria paroxística nocturna (enfermedad de MarchiafavaMicheli); trabajó en glomérulonefritis post estreptocóccica, en meningitis meningocóccica, and so on ${ }^{11}$. Fue médico personal de tres Papa, pues era un excelente clínico, quizás porque era hombre de gran cultura general.

Su mayor contribución al estudio de la malaria fue la demostración de su transmisión por la sangre del enfermo, tarea en que había fracasado el francés, que ni pudo cultivar el parásito ni inocularlo en animales de laboratorio. En colaboración con Celli, Marchiafava desarrolló un trabajo que hoy habría espantado a un comité de ética, inoculando, vía subcutánea e intravenosa, sangre de enfermos palúdicos en enfermos mentales, pensando quizás que, por su condición neurológica, eran “desechables”. Total, cuando enfermaban les daban quinina... Transcribimos textualmente:

Obs. III. Hombre de treinta y dos años, afectado de esclerosis en placas, indemne de paludismo.

El 6 de septiembre, inyección subcutánea de sangre palustre, que no es seguida de ningún efecto.

El 13, inyección intravenosa de 1 gramo de sangre tomada de un enfermo afectado por caquexia palúdica con accesos de fiebre irregulares.

El 20 (siete días después de la inyección), acceso de fiebre, que se repite los días siguientes. El trazado térmico, unido a la observación, es el de una fiebre intermitente cuaternaria. Al mismo tiempo el bazo se tumefacta y el examen de sangre revela la aparición de hematozoarios del paludismo. La fiebre cede fácilmente al sulfato de quinina.

Hay otros ejemplos igualmente horribles, como el de un adolescente de 16 años con mielitis transversa, sometido a varios inyecciones intravenosas "exitosas". El trabajo, muy celebrado por la comunidad científica, fue publicado en 1885 en una revista de agricultura y lo citamos, por si alguien puede encontrarlo ${ }^{12}$.

Sorprende a muchos que hubiera abundante malaria en Europa en el siglo XIX, pues siempre asociamos el paludismo a los países “tropicales”, pero estaba presente en Inglaterra, por ejemplo, y era endémica en
Grecia y en Italia, donde se la consideraba una de las enfermedades inevitables de la infancia, como el sarampión y otras "pestes". Precisamente, "paludismo" deriva del término italiano palude, del latín palus, pantano, en tanto que también es italiano "mal'aria”, aire malo, y Torti, pensando que este aire malo causaba la enfermedad, la llamó así. De los pantanos, se decía, brotaban "efluvios" o vapores plenos de "miasmas", “animálculos” o sustancias imperceptibles que causarían la fiebre. Y ya en la Antigüedad, hay descripciones de este mal por Livio, Varron, Vitrubio, Celso y Columela; por supuesto, también sale el inevitable Hipócrates al baile, pues algunos autores han querido ver el paludismo en sus descripciones de las fiebres ternarias y cuaternarias, que relacionaba con las lluvias y las aguas estancadas ${ }^{13}$. A mayor abundamiento, recordemos que Laveran viajó a la zona romana para su mejor estudio, de manera que no nos sorprenda la destacada participación de los científicos italianos en la historia que nos ocupa.

En 1878, Henry James publicó una bellísima nouvelle, hoy casi olvidada, que se desarrolla en Italia, en que su heroína, la joven y liberal norteamericana Daisy Miller, desafiando los convencionalismos de la época, se pasea de noche con su amigo Giovanelli por las ruinas del Coliseo, siendo descubierta por su admirador norteamericano, quién le pregunta cuánto tiempo lleva allí, y ella contesta, "con dulzura”:

- Toda la noche. Jamás había visto nada tan bello.

- Me temo -dijo Winterbourne- que la fiebre romana no le parecerá tan bella. Así es como la coge la gente.

Una semana más tarde la chica murió. Fue un terrible caso de fiebre.

Sin embargo, aconsejada por el protagonista, esa infausta noche había corrido a su hotel a tomar una pastilla profiláctica, pues ya estaba disponible la quinina: la corteza de quina-quina, llamada chinchona, ya había llegado desde América en el siglo XVII. Debía su nombre a la condesa de Chinchón, esposa del Virrey del Perú y también era conocida como "polvo de los jesuitas”, pues una y otros habían contribuido a su introducción en Europa, con la bendición del famoso Sydenham. Hay una leyenda sobre su origen:

"Un indio, que estaba medio muerto a causa de la fiebre, se dejó caer cerca de un charco en el que yacía un tronco de árbol. Torturado por la sed, se arrastró hasta llegar al agua, de la cual bebió, y cuyo sabor era el sabor amargo de la corteza del árbol. En esta agua amarga había algo que le hacía disminuir la fiebre, hasta que finalmente se curó del todo. A partir de entonces los indios usaron la corteza de este árbol como remedio para las fiebres" ${ }^{15}$.

En la segunda mitad del siglo XIX se usaba como 
profilaxis en las tropas de varios países europeos, en dosis de 0,3 gr en 2 días $^{16}$; su éxito se traduce en varias recomendaciones, como ésta de Van Buren a la Comisión Sanitaria de los Estados Unidos:

"Veinte marineros y un oficial debían ser enviados a Sierra Leona para trabajar allí durante la jornada; a los marineros se les administró corteza de quinquina, pero el oficial rehusó tomarla: fue la única persona que tuvo la fiebre. Más tarde, se destacaron dos chalupas del Hydra para explorar el río Sherbo, estuvieron ausentes por una quincena; cada día los hombres tomaban quinquina en vino, conforme a las instrucciones que habían recibido. Ni un solo hombre fue afectado por la fiebre, aunque la región explorada pasaba por ser una de las más insalubres de la costa. La tripulación de una tercera chalupa permaneció apenas dos días en la misma región y en la misma época; los hombres no tomaron quinquina y fueron todos atacados, excepto el oficial al mando" $" 17$.

Abundando en la profilaxis, se estimaba que también el eucalipto compartía las bondades de la quinina, al punto que Ramel introdujo su cultivo en Francia para contribuir al saneamiento de las zonas pantanosas. Una bella historia de Torelli ilustra el punto:

"Existe cerca de Roma, fuera de la puerta de Ostia, en el lugar llamado de Las Tres Fuentes, un convento que estaba abandonado desde mucho tiempo a causa de su insalubridad y que llevaba el significativo nombre de Tumba. En 1868, el Papa Pío IX donó el convento a los trapenses, quienes tomaron posesión, pero en condiciones deplorables. En los primeros años el lugar era tan malsano, que los religiosos no podían dormir allí; volvían en la tarde a Roma y retornaban a las Tres Fuentes al salir el sol.

Las primeras plantaciones de eucaliptos se hicieron en 1869. En 1876, la disminución era tal, que los trapenses podían habitar el convento durante la noche sin ser afectados por la fiebre. En 1877, el número de eucaliptos pasaba de 2.500. Fue cedido a los trapenses un espacio de 400 hectáreas a cambio de plantar ahí 100.000 eucaliptos en diez años"18.

Ya se sabía que el paludismo se debía a un parásito, que podía transmitirse por la sangre de un enfermo a otro, pero faltaba el “cómo”, es decir, el vector. Laveran había intuido el rol de un mosquito transmisor, al decir en el Congreso Internacional de Higiene en Budapest en 1894: "Después de haber intentado en vano encontrar el parásito en el aire o en el suelo de las zonas palúdicas, y fracasado en cultivarlo en los más variados medios...me llevaron a pensar que el microbio de la malaria vivía en el medio exterior en estado de parásito, sospechando de los mosquitos, que abundan en todas esas localidades y que ya desempeñan un papel muy importante también en la propagación de la filariasis... En aquella época esta opinión sobre el papel de los mosquitos fue considerada por la inmensa mayoría de los investigadores como muy poco probable”19. La teoría estaba, mas no la demostración. Pero ésa es otra historia: terminemos por ahora con Laveran.

El Premio Nobel fue por primera vez discernido en 1901 y lo ganó Von Behring, por el suero antidiftérico, antes que el mismo Koch; al año siguiente fue para Ronald Ross, por la transmisión de la malaria... Laveran, descubridor del parásito, lo logró recién en 1907. Investigador hasta el tuétano y generoso en demasía, donó la mitad al Instituto Pasteur donde era Jefe de Servicio Honorario desde 1897, para remodelar y equipar el Laboratorio de Enfermedades Tropicales ${ }^{20}$. No escribió novelas ni filosofías, como Ronald Ross, de quien nos ocuparemos próximamente, ni comentó a Horacio, como Marchiafava, ni plantó eucaliptos (tener un hijo, escribir un libro, plantar un árbol...) pero estas debilidades no le restan méritos.

\section{Resumen}

El descubrimiento en 1880 del parásito de la malaria por el investigador francés Alphonse Laveran enfrentó por casi diez años la tenaz negación del italiano Ettore Marchiafava, quien veía en los elementos parasitarios sólo formas degenerativas de los eritrocitos. El reconocimiento para Laveran llegó en 1889 con el Premio Breánt y luego el Nobel de 1907, la mitad del cual donó al Instituto Pasteur.

Por su parte, Marchiafava demostró la transmisión de la malaria en el hombre por la sangre de los enfermos, en trabajos experimentales hoy día inaceptables para un comité de ética.

A partir del texto clásico de Laveran "Du paludisme et de son hématozoaire”, publicado en 1891, se revisa la historia de este descubrimiento en las palabras del autor. 


\section{Referencias}

1.- Laveran A. Du paludisme et de son hématozoaire. G.Masson, Éditeur, Libraire de l'Académie de Médecine, Paris 1891; VII (Preface).

2.- Ibid; VIII (Preface).

3.- Nobel e-Museum. Alphonse LaveranBiography. http://www.nobel.se/medicine/ laureates/1907/laveran-bio.html

4.- Fischbach G. Guerre de 1870. Le siège de Strasbourg. L'Imprimerie Alsacienne a Strasbourg, Strasbourg 1897; II: 14.

5.- Laveran A. Nature parasitaire des accidentes de l'impaludisme. Description d'un nouveau parasite trouvé dans le sang des maladies atteints de fiebre palustre (Avec deux planches). Maisson Ballière et fils, Éditeurs, Paris 1881).

6. - Marchiafava E, Celli A. Weitere Untersuchungen über die Malariainfection. Fortschritte der Medicin, München 1885; 3:
787-806.

7.- Laveran A. Traité des fièvres palustres. O.Doin, Éditeur, Paris 1884; 196-8.

8. - Laveran A. Du paludisme et de son hématozoaire. G.Masson, Éditeur, Libraire de l'Académie de Médecine, Paris 1891; 52-5.

9.- Biographies by country. Ettore Marchiafava. www.whonamedit.com

10.- Soulié E. Étiologie du paludisme. Communication à la Societé de Biologie. C R de la Soc Biologie 1888; 766-7.

11.- Dorland's Illustrated Medical Dictionary. 28th Ed. W.B. Saunders, Phi 1994; 987.

12.- Marchiafava E, Celli A. Nuove ricerche sulla infezione malarica. Annali di Agricoltora, Roma 1885.

13.- Buj Buj A. De los miasmas a malaria. www. Permanencias e innovación en la lucha contra el paludismo. Scripta nova. Revista electrónica de Geografía y Ciencias sociales 2000 (Agosto 1); 69 (42).
14.- James H. Daisy Miller. Bibliotex S.L. Madrid 1999; 87-92.

15.- Haggard HW. El médico en la historia. $4^{\circ}$ ed. Editorial Sudamericana, Buenos Aires 1952; 431.

16.- Viry Ch. Principes d'hygiene militaire. Ancienne Maisson Delahaye. L. Bataille et cie, Éditeurs, Paris 1896; 596.

17.- Evans J. Essais d’hygiene et de thérapeutique militaires. G.Masson, Éditeur, Libraire de l’Académie de Médecine, Paris 1881.

18. - Laveran A. Du paludisme et de son hématozoaire. G.Masson, Éditeur, Libraire de l’Académie de Médecine, Paris 1891; 215-6.

19.- Laveran and the discovery of the Malaria parasite. Department of Health and Human Services. Centers for Disease Control and Prevention. http://www.cdc.gov/Malaria/ history/laveran.htm.

20.- Charles Louis Alphonse Laveran (18451922). http://www.historiadelamedicina.org. 